\title{
APPLICATION OF GIS SOFTWARE IN LOCAL ADMINISTRATION: THE EXAMPLE OF CON CUONG REGION, NGHE AN PROVINCE, VIETNAM
}

\author{
Nguyen An Thinh \\ Lo Thi Hong Van
}

Vietnam National University, Hanoi, Vietnam

Lydmila A. Guzikova

Peter the Great St. Petersburg Polytechnic University, St. Petersburg, Russia

\author{
Dinh Thi Thu Huyen \\ Do Thi Huyen Trang \\ Doan Thi Thu Hien
}

Vietnam National University, Hanoi, Vietnam

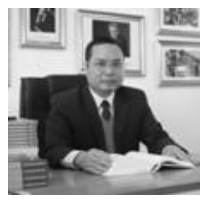

\begin{abstract}
Nguyen An Thinh
Dr. in Environmental and Natural Resource Management, Vietnam National University, Hanoi, Vietnam.

Assoc. Professor, Dean of the Faculty of Development Economics at University of Economics and Business, Vietnam National University, Hanoi. He also currently acts as the Vice-President of the International Association of Landscape Ecology in Vietnam region (VN-IALE).

His research focuses include geography of Vietnam, human geography, environmental economics, and mountainous landscape ecology. Published over 30 papers in international peer reviewed journals, 20 text books, and about 100 papers in local Vietnamese scientific journals.

E-mail: thinhhus@gmail.com
\end{abstract}

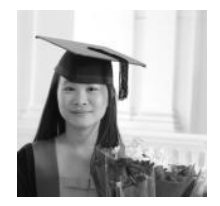

\section{Lo Thi Hong Van}

Dr. in Economics, Lecture of Department of public policy, of the Faculty of Development Economics at University of Economics and Business, Vietnam National University, Hanoi, Vietnam.

Research interests: public policy management, strategic management, human resources, the sustainable economy, management for sustainable development, management innovation.

Published over 20 papers in international journals.

E-mail: hongvan289@gmail.com

\section{Lyudmila A. Guzikova}

Doctor of Economic Sciences, Professor of Graduate School of Industrial Economics, Peter the Great St. Petersburg Polytechnic University, Russia.

Research interests: mathematical methods in economy and finance, sustainable development, financial management, housing economy. Published more than 150 scientific works in international peer reviewed journals proceedings of the national and international conferences and other.

E-mail: guzikova@mail.ru

Dinh Thi Thu Huyen

Do Thi Huyen Trang

Doan Thi Thu Hien

Students at University of Economics and Business, Vietnam National University, Hanoi, Vietnam.

Research interests: public policy management, strategic management, human resources, the sustainable economy. 
The use of GIS software is helping to digitize databases for government purposes at all levels. The article provides an example of the GIS software application for assessing the availability of basic socioeconomic services for the residents of Kon Kuong, Nghe An. The article focuses on the analysis of the role of factors influencing the availability of public services in the Kon Kuong region of NgheAn province based on the analytical hierarchy processing (AHP) method. A map of the availability of socioeconomic services for the Kon Kuong area has been digitized using the ArcGIS software, version 10.5. The map of the availability of socioeconomic services would allow political decision-makers to develop plans for the development of the region through minimization of the imbalances in access to public services among the population. The results of the study are applicable to not only Vietnam, but also to other countries and regions willing to assess the level of population access to public services.

Keywords: digital transformation; local government; GIS software; Vietnam; public services; population access

\section{Introduction}

Sustainable development has become an inevitable trend in all the countries of the world (Guzikova \& Van, 2019). In developing countries, such as Vietnam, inequalities in socioeconomic development between localities make it difficult to achieve sustainable development goals. The Industry 4.0 has completely changed the mode of operations within political, economic and social systems (Van \& Guzikova, 2020). Local governments require digital transformation in order to minimize inequalities in governance across the regions of Vietnam. The use of software technologies makes it possible to increase the efficiency of public administration at the local level.

GIS (Geographic Information System) software is a tool used to collect, manage and analyze data from geospatial space, thereby performing map editing, storing map data, and manipulating embedded maps with objects and phenomena in real space. GIS allows users to perform visual monitoring using maps and 3D images of scenes (Chang, 2016).

Equity in access to basic socioeconomic services remains limited as there are large disparities between regions, especially among ethnic minorities and in mountainous areas. In this study, GIS software will be used to assess the population's ability to access socioeconomic services.

Con Cuong Region is a mountainous region located in the southwest of Nghe An province. The total natural area of the study area is $174,243.01 \mathrm{~km} 2$, of which, about $2 / 3$ of the area is hilly. Con Kuong has 12 communes, 1 city (with 2 border communes), and 127 villages with the population of 71,973 people, including nine ethnic groups (Konkuong Nge An Electronic portal, 2021).

According to the data of the 3rd Congress of Ethnic Minority Deputies in the region of Kon Kuong (Nghe An) in 2019, the currently used state method for reducing poverty is not effective enough, as some ethnic policies have been implemented slowly and have not yet attracted people's attention. Identification of the factors influencing the ability to access social and economic services for the population of the Kon Kuong region is a necessity for effective implementation of the socio-economic development policy in the Kon Kuong region. 


\section{APPLICATION OF GIS SOFTWARE IN LOCAL}

Subject of the research: Availability of socioeconomic services for the population of Kon Kuong region, Nghe An province as of 2015 to 2021. The study has been focused on assessing the accessibility across six groups of services: healthcare, education, politics, traffic, land use, and altitude. These are the most important services to meet the minimum needs of people, especially those living in the mountainous areas of Kon Kuong.

Research Objectives: To provide a scientific basis for quantifying population accessibility to socioeconomic services in Kon Kuong region, Nghe An Province, using GIS software.

\section{Research methods}

A method of comparative analysis of data from the locally available documents such as reports, cadastral map information, cadastral records of the Department of Natural Resources and Environmental Management, has been used. The collected data is displayed on a digital map with the advanced settings for the area of study by extracting specific areas from the platform using ESRI ArcGIS Ver.10.5. (GIS) software.

Analytical Hierarchy Process (AHP) method has been then used to determine the role of factors impacting population accessibility to various socioeconomic services in the region under study.

\section{Results}

\section{Theoretical Foundations of Geographic Information Systems (GIS)}

According to the ESRI (the Environmental System Research Institute), Geographic Information System (GIS) is a general organization of four components: computer hardware, software, geographic document and operator, which are designed to work effectively to receive, store, manage, analyze and display all types of geographic data (Understanding GIS, 2021).

The first and the main goal of GIS is to work with data systems in a geospatial environment.

In 1979, Ducker defined it as follows: "GIS is a special case of an information system in which a database consists of observations of spatially distributed objects, possible operations with events and defined in space, such as a line, point, area" (Sadoun \& Saleh, 2010). According to the British-American geographer Michael Frank Goodchild, GIS is a system that uses databases to answer questions about the geographic nature of geographic features (Sui \& Goodchild, 2001). Another ESRI definition reveals that GIS is a computer system that stores and links geographic data to map elements. From there, to expand the capabilities of information processing, displaying information and creating cartographic products, processing results and models.

Thus, GIS can be defined as an information system that uses input data, analytical operations, and output databases that are geographically and/or geospatially linked to aid in collection, storage, management, processing, analysis, and display of spatial information. In the real world, this would help to solve the problems of aggregating information for various purposes set by people, such as: decision support for planning, land use, natural resources, environment, traffic. 
Nowadays GIS is increasingly used to support urban development planning and storage of administrative data.

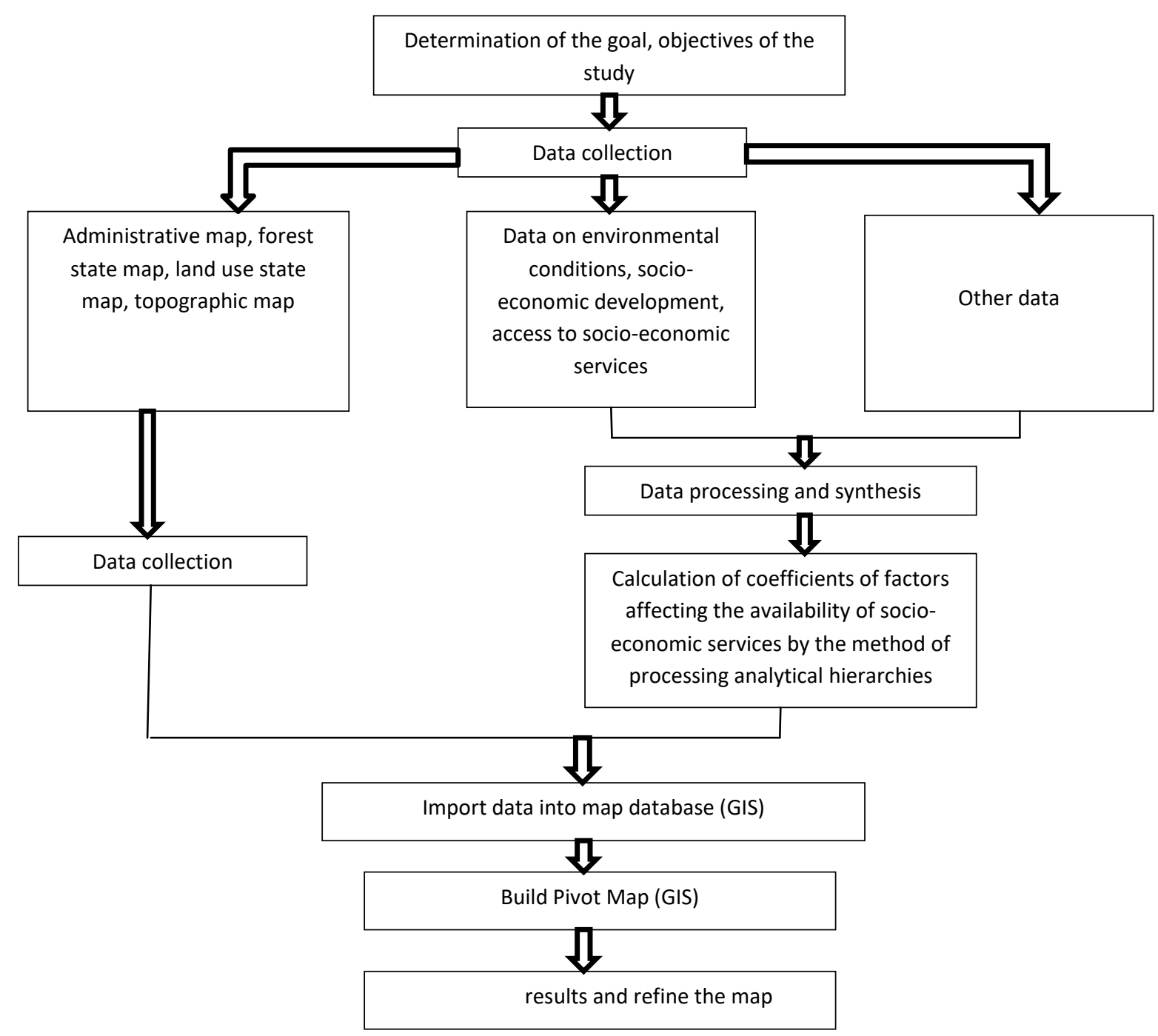

Figure 1 - Procedures of using GIS software to assess the accessibility socioeconomic services to local population

(Source: Compiled by the authors)

The process of using GIS software to assess the accessibility of socioeconomic services to local population

The process of using GIS software to assess the accessibility of various socioeconomic services is shown in Figure 1.

The process of using GIS software to assess the accessibility of socioeconomic services to local population can be divided into four stages:

Step 1. Data collection and processing, component map data

Step 2: Installing the component card 


\section{APPLICATION OF GIS SOFTWARE IN LOCAL} services.

Step 3. Developing a comprehensive map to assess the availability of socioeconomic

Step 4. Evaluating the overall situation and proposing solutions to improve the accessibility of services.

The Analytical Hierarchy Process (AHP) is a decision-making method that provides an order of criteria by which a decision-maker can make the most reasonable final decision (Saaty \& Vargas, 2001). Based on the collected documents and data, the study focuses on analyzing and comparing six factors, including healthcare $(\mathrm{H})$, education $(\mathrm{E})$, politics $(\mathrm{P})$, traffic $(\mathrm{T})$, land use $(\mathrm{L})$ and altitude $(\mathrm{Hi})$. The importance of these factors is reflected in weighted values through subjective comparisons between each pair of factors, as shown in Tab. 1 below.

Table 1 - AHP of the factors affecting the level of accessibility of socioeconomic services (Source: compiled by the authors)

\begin{tabular}{|c|c|c|c|c|c|c|c|}
\hline & $\begin{array}{c}\text { Road } \\
\text { traffic (T) }\end{array}$ & $\begin{array}{c}\text { Education } \\
(\mathrm{E})\end{array}$ & $\begin{array}{c}\text { Health- } \\
\text { care (H) }\end{array}$ & Politics (P) & $\begin{array}{c}\text { Land use } \\
(\mathrm{L})\end{array}$ & $\begin{array}{c}\text { Altitude } \\
(\mathrm{Hi})\end{array}$ & Coefficient \\
\hline $\mathrm{T}$ & & 5 & 2 & 2 & 2 & 4 & 0,326 \\
\hline $\mathrm{E}$ & & & $1 / 3$ & $1 / 4$ & $1 / 2$ & $1 / 2$ & 0,057 \\
\hline $\mathrm{H}$ & & & & $1 / 4$ & $1 / 2$ & 2 & 0,135 \\
\hline $\mathrm{P}$ & & & & & 2 & 3 & 0,239 \\
\hline $\mathrm{L}$ & & & & & & 2 & 0,161 \\
\hline $\mathrm{Hi}$ & & & & & & & 0,082 \\
\hline
\end{tabular}

The levels of accessibility of socioeconomic services to population are then expressed as the following equation:

$$
\mathrm{Y}=0,326^{*} \mathrm{~T}+0,057 * \mathrm{E}+0,135^{*} \mathrm{H}+0,239^{*} \mathrm{P}+0,161 * \mathrm{~L}+0,082 * \mathrm{Hi}
$$

where $\mathrm{Y}$ is the level of accessibility of socioeconomic services to population.

Table 2 - Data for the summary map of the availability of socioeconomic services to population

(Source: calculated by the authors)

\begin{tabular}{|c|c|c|c|}
\hline $\begin{array}{c}\text { The level of accessibility of } \\
\text { socioeconomic services to population }\end{array}$ & Grade & $\begin{array}{c}\text { Square } \\
(\mathrm{Ha})\end{array}$ & Interest (\%) \\
\hline Excellence & 4 & 29911,2 & 17,20 \\
\hline Good & 3 & 34364 & 19,76 \\
\hline Average & 2 & 38216,64 & 21,98 \\
\hline Low & 1 & 71399,68 & 41,06 \\
\hline
\end{tabular}


Thus, we can state that transport and politics are the factors that most affect the availability of socioeconomic services for local population in the Kon Kuong area. This equation shows that to improve people's access to public services, priority should be given to investments in transport, policy design and improvement, school and hospital infrastructure, and land use efficiency improvements.

The results of mapping the levels of accessibility of socioeconomic services for local population in the Kon Kuong area are shown in Fig. 2. The summary map shows the most intuitive results in assessing the availability of socioeconomic services in Kon Kuong.

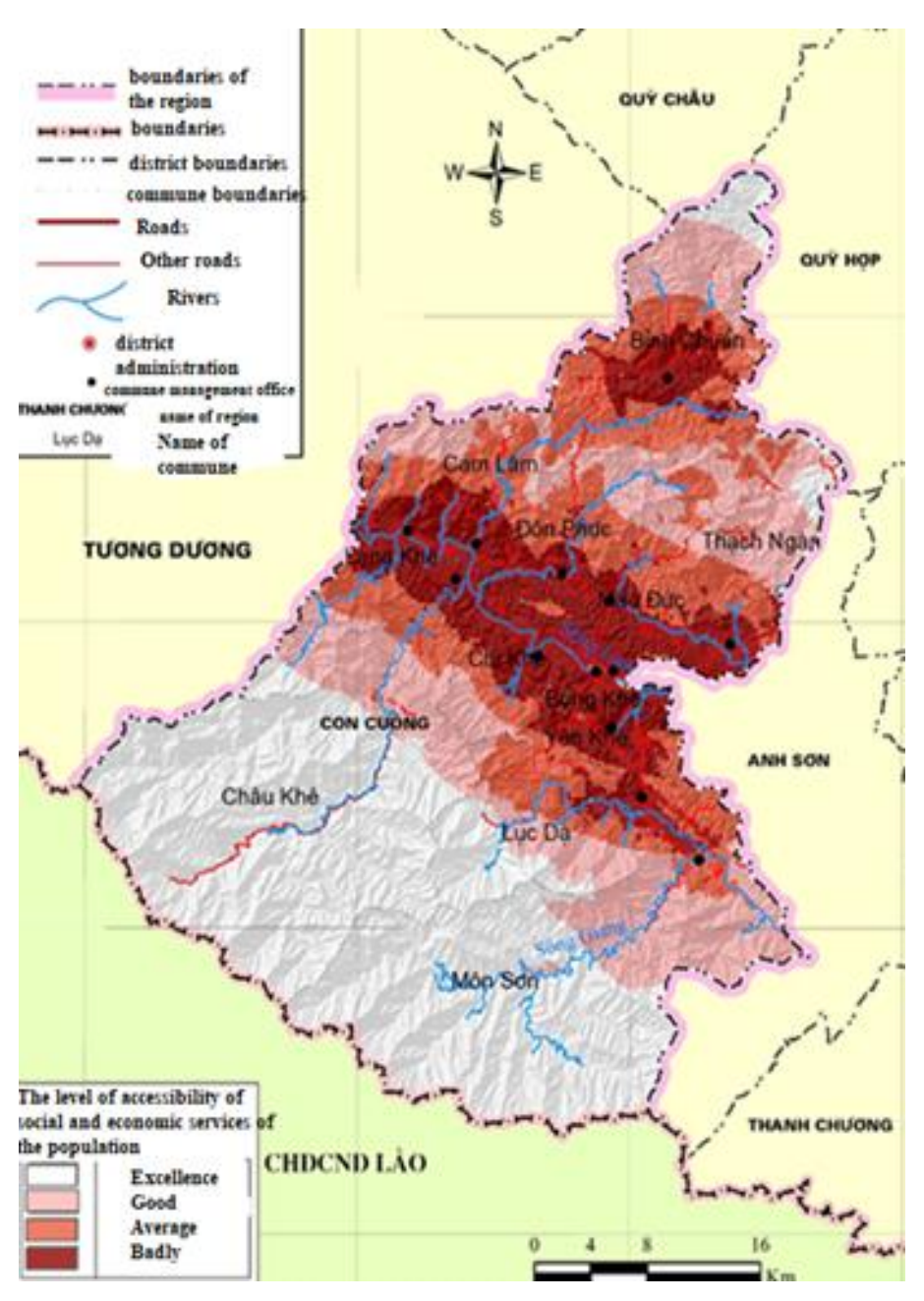

Figure 2 - Summary map of the levels of socioeconomic services accessibility to population in the Kon Kuong area

(Source: designed by the authors using GIS platform)

The map clearly shows the parts of the area that provide the most of public services; they are concentrated around the important roads (national highways and provincial roads). These roads allow people to move more smoothly to social service points.

Thus, the role of the transport system is extremely important in helping the population improve their access to basic services and thus meet the minimum needs of the people. 


\section{APPLICATION OF GIS SOFTWARE IN LOCAL}

\section{Conclusion}

Assessing the availability of socioeconomic services to local communities is a contemporary quantification method that provides reliable accuracy through the use of modern assessment technologies such as Geographic Information System (GIS).

In addition, applying the AHP method, we were able to calculate the weighted values (the coefficient expresses the fraction of importance) for each research factor (healthcare, education, politics, traffic, land use, altitude) by subjectively comparing the level of importance of each aspect, thereby contributing to the construction of a general map.

\section{References:}

Guzikova, L. A. \& Van, L. T. H. (2019). Sustainable development as national doctrine: experience of Vietnam. Economic and Social Development: Book of Proceedings, 1011-1021.

Chang, K. T. (2016). Geographic information system. International Encyclopedia of Geography: People, the Earth, Environment and Technology, 1-9.

Konkuong Nge An Electronic portal. (2021). Available at: http://concuong.nghean.gov.vn/wps/portal/concuong.

Understanding GIS. (2021). Available online at: https://www.esri.com/en-us/arcgis/products/arcgisonline/overview.

Sadoun, B. \& Saleh, B. (2010). A Geographic Information System (GIS) to define indicators for development and planning in Jordan. International Conference on e-Business (ICE-B), 1-7.

Sui, D. Z. \& Goodchild, M. F. (2001). GIS as media? International Journal of Geographical Information Science, 15 (5), 387-390.

Saaty, T. \& Vargas, L. (2001). Methods, Concepts and Applications of the Analytic Hierarchy Process. Kluwer Academic Publishers, Boston.

Van, L. T. H. \& Guzikova, L. A. (2020). Industry 4.0 in Vietnam: strategic planning experience. Asia and Africa Today, 8, 64-68.

Paper submitted

Paper accepted for publishing

Paper published online
07 November 2021

14 December 2021

31 January 2022 